\title{
Localization of Gamma-Glutamyl Transpeptidase in the Epithelial Transitional
}

\section{Zones}

\author{
BY \\ Toshiko KOMATSU \\ Department of Anatomy, School of Medicine, Keio University \\ Shinanomachi, Shinjuku, Tokyo 160
}

-Received for Publication, August 23, 1986-

Key Words Gamma-glutamyl transpeptidase, transitional zone, rat

Summary: The localization of gamma-glutamyl transpeptidase (gamma-GTP) activity in epithelial transitional zones, where two kinds of epithelial cells were present, was studied in normal adult rats by using the enzyme histochemical method.

Gamma-GTP activity was observed without exception in cells of the superficial layer in the squamous epithelial side the following transitional zones: esophago-gastric junction, rectoanal junction, utero-vaginal junction and the excretory duct of the laryngeal gland (stratified squamous-simple columnar epithelial junction); fossa navicularis and conjunctiva of the eyelid (stratified squamous-stratified columnar epithelial junction); epiglottis, junction of the nasal pharynx and epiglottis and junction of the oral pharynx and larynx (stratified squamouspseudostratified ciliated epithelial junction); and the junction between the inside and the outside of the inner root sheath in the epithelial hair follicle.

Higher gamma-GTP activity was generally seen in the epithelial cells of transitional zones than in the neighboring epithelial cells.

As gamma-GTP activity is specifically present in the epithelial cells of transitional zones, it is a useful marker for identifying the sites of the transitional zones. The epithelial cells in the transitional zone may undergo more extensive proliferation or perform more active function in the transfer of amino acids and peptides than other regular epithelial cells do.

The areas, where the arrangement of the epithelial lining cells changes from one part to another are called epithelial transitional zones. The arrangement of the epithelial cells in the transitional zone abounds in variety, comparing with that in the other parts of the body. The esophago-gastric junction, the cervico-vaginal junction, and the recto-anal junction are well known as epithelial transitional zones. The cervicovaginal junction is notorious for being the area most prone to uterine cancer and the site where is sensitive to the change of the hormonal condition (24). The epithelial cell of these transitional zones may be of undifferentiated nature or have the manifold potentiality in the morphological differentiation. However, almost no attention has been paid to the distribution of enzymes in these epithelial transitional zones. Gammaglutamyl transpeptidase (Gamma-GTP) is known to be one of the carcinoembryonic enzymes $(7,10,11)$ which appear in undifferentiated tissues, in some stage of fetal organs $(3,11,17,18,19,25)$ and in malignant tissues $(7,12,13,14,15,16,25$, $27,28,34,36)$.

These facts suggests that gamma-GTP activity may have a tendency to be elevated in organs in certain conditions which 
have deviated from the normal state. Therefore, it is thought to be worthwhile to observe the distribution of gamma-GTP in the transitional zone and compare it with that in the epithelia on both sides of this intervening zone.

This study dealts with the study on the localization of gamma-GTP in the epithelial transitional zones by the enzyme histochemical method to analyze the character istics of the cells of that zone.

\section{Materials and Methods}

1. Enzyme histochemical staining of gammaGTP

Tissue samples were taken from the following transitional epithelial zones of adult Wistar rats; the portions between esophagus and stomach, rectum and anus, uterus and vagina, nasal pharynx and esophagus, oral pharynx and larynx, and male urethra, fossa navicularis and between the epidermis and the mucous epithelium of the conjunctiva of the eyelid.

The tissue samples were fixed in $4 \%$ paraformaldehyde in $0.1 \mathrm{M}$ phosphate buffer at pH 7.2 for $4 \mathrm{hr}$. The fixed tissues were washed in $0.85 \% \mathrm{NaCl}$ in $0.01 \mathrm{M}$ phosphate buffer, $\mathrm{pH} 7.2$ (PBS), containing $7.5 \%$ sucrose for $4 \mathrm{hr}$, dehydrated in a series of alcohols and embedded in paraffin. Paraffin sections about $4.5 \mu \mathrm{m}$ in thickness were prepared and mounted on glass slides.

The localization of gamma-GTP activity was studied by Rutenburg's method (28).

In order to ascertain the specificity of the staining, the following control staining procedures were carried out, a) omitting substrate, b) omitting effector, and c) treatment of tissue sections with PBS at $80^{\circ} \mathrm{C}$ for $10 \mathrm{~min}$.

2. Enzyme histochemistry of other enzymes

Distribution of enzymes other than gamma-GTP was studied in the recto-anal and utero-vaginal junctions in parallel with gamma-GTP to characterize the epithelial cells in transitional zones. They were alkaline phosphatase (ALP) (5), and leucine aminopeptidase (LAP) (23) as the onco-fetal enzyme (16), and lactate dehydrogenase (LDH) $(9,37)$, and glucose-6-phosphatase (G6P) (35) as the enzyme reflecting anaerobic metabolism of cells (31).

Tissue blocks were fixed with $4 \%$ paraformaldehyde in $0.1 \mathrm{M}$ phosphate buffer, $\mathrm{pH} \mathrm{7.2,} \mathrm{for} 3 \mathrm{hr}$. Frozen sections were prepared for the study of these enzymes. The substrates were omitted from the reaction medium in the control experiments.

\section{Results}

1) Distribution of gamma-GTP

The distribution of the enzyme was studied in the junctions between stratified squamous and simple columnar epithelium, between stratified squamous and stratified columnar epithelium and between stratified squamous and pseudostratified ciliated epithelium, and also in the epithelial hair follicle.

a. Transitional zone between stratified squamous and simple columnar epithelia:

Gamma-GTP activity was commonly seen in the stratified squamous epithelial side of the esophago-gastric (Fig 1,2), recto-anal (Fig. 4,5), utero-vaginal junctions (Fig. 3) and that of the excretory ducts of the pharyngeal or laryngeal glands (Fig. 7). In the above junctional regions, enzyme activity was seen in the upper layers of the stratified squamous epithelium. Occasionally, the positive reactions was confined to the superficial keratinized layer (Fig. 3, 4). Neither the simple columnar (Fig. 1, 2-GS., Fig. 3-U., Fig. 4,5-R., Fig. 7-T) nor the stratified squamous cells localized on either sides of the intervening transitional zone (Fig.1-A., Fig. 4-C., Fig. 7-O) showed any gamma-GTP 
activity. However, sometimes, faint or moderate activity was observed in the columnar cells in the utero-vaginal junction. Reaction products seemed to be located not only along the cell membrane but also in the cytoplasm (Fig. 2, 4, 7).

b. Transitional zone between stratified squamous and stratified columnar epithelia:

Strong gamma-GTP activity was observed in the stratified squamous epithelium in the fossa navicularis but not in that of the urethra in the glans penis (Fig. 8). The gamma-GTP positive cells were stratified and showed the intermediate form between columnar and squamous, being more like squamous than columnar epithelium. Occasionally, the enzyme activity was also seen in the stratified columnar epithelium of fossa navicularis.

In the conjunctiva of the eyelid, weak reaction of gamma-GTP activity was observed only in the stratified squamous epithelium of the lid margins.

c. Transitional zone between suamous and pseudostratified ciliated epithelia:

The junctions between the oral pharynx and the larynx (Fig. 9-OPL), between the nasal pharynx and the epiglottis (Fig. 9NPE), and between the larynx and the epiglottis (Fig. 9-LE) were examined for gamma-GTP activity. The transitional zone is defined not as clearly as in the other areas, since the nature of the epithelia in these junctions change gradually from stratified squamous epithelium to pseudostratified ciliated epithelium. Stratified columnar cells were usually present between these two kinds of epithelia. Both stratified squamous and stratified columnar epithelial cells showed gamma-GTP enyme activity in this area.

Gamma-GTP activity was not observed in the stratified squamous cells located at some distance from the transitional zones. Other kinds of neighboring epithelial cells generally showed no gamma-GTP activity or much lower activity than the stratified squamous epithelium of the transitional zones.

d. Epithelial hair follicle:

Gamma-GTP activity appeared inside the hair follicle in the pubic skin, but it was not present in the portion above the place where the sebaceous glands opened into the hair follicle. Accordingly, gamma-GTP is shown to be localized in the inner root sheath.

Most probably, this area represented one of the variations in epithelial transitional zones. The transitional parts were seen between the upper and lower portions of the opening of the sebaceous glands, and between the hair cortex and the outer root sheath or between the inside and the outside of the hair follicle. When the hair was cut longitudinally, as shown in Fig. 10, the transitional portion was also seen between the upper and lower parts, taking the opening of the sebaceous gland as a cardinal point. In the cross section of the hair follicle as shown in Fig. 11, the transition was seen between inside and outside of the hair follicle.

\section{2) Distribution of enzymes other than gamma-GTP}

Among the enzymes examined in this study, only ALP activity was found in the recto-anal and utero-vaginal junctions.

Alkaline phosphatase activity was observed in the squamous epithelium of the transitional zone in the recto-anal junction. Distribution of ALP active cells was almost the same as that of gamma-GTP active cells (Fig. 6).

\section{3) Control staining for Rutenburg's method for gamma-GTP}

No reaction was observed in the sections treated with the reaction medium without substrate, and the enzyme activity of gammaGTP was entirely destroyed by heat treatment. Only a weak reaction was seen when 
the sections were incubated with the reaction medium omitting the effector, glycylglycine. The reaction products tended to be diffusible and unstable without glycylglycine.

\section{Discussion}

1) Presence of gamma-GTP in the superficial layer of the transitional zone

The results of the present study show that, in general, the gamma-GTP activity is specifically high on the stratified squamous epithelial side in the epithelial transitional zone.

At the beginning of this study, it was expected that gamma-GTP would be found in the cells of the basal layer where the mitosis takes place and undifferentiated cells are present, because gamma-GTP is known as a carcino-embryonic protein which appears in rather undifferentiated tissues $(7,11)$. However, high activity of gamma-GTP was observed in the limited cells in the superificial layers, but not in the cells of the basal layer of either the stratified squamous epithelium or the other kinds of epithelia. Gamma-GTP activity was not observed in the basal layer where mitosis occurs. On the basis of these data in these areas, gamma-GTP is not regarded as a general marker for the mitotic zone. It was reported recently that the activity of gamma-GTP increases with DNA restoration due to poly-ADP- ribosylation (28). Taking this into consideration along with the fact that no gamma-GTP appears in the basal layer where the mitosis is taken place, in the transitional region, gamma-GTP in this area may not be related to the synthesis of nucleic acid.

Most probably, the epithelia of the transitional zones, in the superficial layer may still preserve the physiological function of gamma-GTP, even though the cells were flattened and looked as if they were fully keratinized.

2) Sites in common with gamma-GTP and ALP

When frozen sections from the rectoanal and utero-vaginal regions were examined with enzyme histochemical technique for ALP, LAP, LDH, G6P and for gammaGTP, ALP activity alone was positive at the same site as gamma-GTP was present.

Both ALP and gamma-GTP are cell membrane-bound glycoproteins $(16,4)$, and they are the markers of for the carcinoma in liver $(16,12)$. Cell membrane glycoprotein usually binds to the membrane with the C-terminal side of an amino acid, and the $\mathrm{N}$ terminal side is exposed towards the outer site of the membrane $(32,21)$. In contrast, gamma-GTP and ALP bind to the membrane with the $\mathrm{N}$-terminal side of the peptide ( 8 , 32). The process of this synthesis is attracting much interest. The fact that the enzymes which appear on the surface of precancerous cell, such as gamma-GTP and ALP, are present in squamous cells of the transitional region may suggest that the changes in the process of synthetic process of glycoproteins is being taken place in the cells (30). The presence of ALP activity in the gammaGTP-positive cells indicates that this group of cells is involved in some different types of metabolism from that of surrounding cells.

The feature of coexistence of ALP and gamma-GTP is, in a certain sense, similar to that in the brush border of the proximal convolution of kidney. But, it is rather easily understandable that a certain acceleration of the cellular function occurred in the transitional zone by contacting two different types of epithelia with each other, than speculating that both enzymes play, like in kidney $(21,22)$, important roles of transporting amino acids, peptides, water and electrolytes in such a narrow area of 
contact.

3) The possible role of gamma-GTP in the transitional region

The reason why gamma-GTP activity appears in such a limited area of the epithelial transitional zones remains within the range of the conjecture. As already mentioned, the cells which show gamma-GTP activity are the squamous in shape and distributed themselves in the upper layer of the squamous epithelium of the transitional zones. Even the squamous shaped cells in the epithelium are negative to the gammaGTP reaction, when they are located in the deeper layer of the epithelium. The columnar or cuboidal cells including the cells of the basal layer are not reactive.

Since gamma-GTP is concerned indirectly with the polymerization of the cytoskeletal proteins by supplying sulphydril groups to these proteins $(20,29)$, it is conjectured that the activity of gamma-GTP in the cells of the transitional zone remained high, because the cytoskeletal proteins in the squamous cells in the upper layers of the transitional epithelium may be forced to keep polymerizing the cytoskeletal proteins, as the shape of these cells undergo continuous alternation by being intervened between two different kinds of the epithelia. Whereas, the enzyme activity is low or negative in the rest of the cells, as the cytoskeletal proteins are in so stable condition in respect to their polymerization that the gamma-GTP activity may not be required.

As for the presence of the gammaGTP activity in the hair follicle, gamma-GTP may be the marker of the initiation of the keratinization in the hair $(7,27)$.

4) Origin and differentiation of the stem cells in the transitional zone.

Stem cells which can differentiate to only one type of cell are called unipotent cells, and those which can differentiate to several types of cells are called multipotent cells (1).

If the stem cells in stratified squamous and simple columnar epithelial transitional zones are multipotent, squamous cells and columnar cells should frequently be mixed, especially in the deep layer along the border line between two epithelia. However the border line was distinct as shown in Fig.4-B. In addition, the gamma-GTP positive cells in Fig. 4-B, located in the deep part, exhibited the shape of the mature cells, and showed the same appearance as the superficial epithelial cells did.

These two points suggest that the stem cell of the squamous cells is different from that of the columnar cells, and each daughter cell is destined to move along different routes, in the process of cell differentiation in these transitional regions.

When and how the differentiation of these cells begins are interesting problems to be solved in the future study.

\section{References}

1) Alberts, B., Bray, D., Lewis, J., Raff,M., Roberts, K. and Watson, J.D.: Molecular Biology of the cell, pp. 550-941, Garland Publshing Inc., New York, 1983.

2) Altahuas, F.R., Lawrence, S.D., Yu-Zhu He, Sattler, G.L., Tsukada, Y. and Pitot, H.C.: Effects of altered [ADP-ribose] n metabolism on expression of fetal functions by adult hepatocytes. Nature, 300: 366-368, 1982.

3) Aurrichio, S., Stellato, A. and Basilio de Vizia.: Development of brush border peptidases in human and rat small intestine during fetal and neonatal life. Pediatr. Res., 15: 991995, 1981.

4) Briere, N., Martel, M., Plante, G. and Petitclerc, C.: Simultaneous visualization of ALP and gamma-GTP in kidney sections. Acta Histochem., 75: 107-110, 1984.

5) Burstone, M.S., in "Enzyme Histochemistry", 1962, Academic Press, New York, 1962.

6) Buxmann, M.M., Kocarnik,M.J. and Holbrook, K.A.: Transglutaminase and transpeptidase. J. Invest. Dermatol., 72: 171-177, 1979. 
7) Cameron, R., Kallen, J., Kolin, A., Malkin, A. and Farber, E.: Gamma-glutamyl transferase in putative premalignant liver cell populations during hepatocarcinogenesis. Cancer Res. 38: 823-829, 1978.

8) Colbeau, A. and Maroux, S.: Integration of Alkaline phosphatase in the intestinal brush border membrane. Biochim. Biophys. Acta, 511: 39-51, 1978.

9) Fahimi, H.D. and Amarasingham, C.R.: Cytochemical localization of lactic dehydrogenase in white skeletal muscle. H. Cell Biol., 22: 29, 1964.

10) Fiala, S. and Fiala, E.S.: Activation by chemical carcinogenesis of gamma-glutamyl transpetidase in rat and mouse liver. J. Nat. Cancer Inst., 51: 151-158, 1973.

11) Fleming, N., Groscurth, P. and Kistler, G.S.: The activity and distribution of gamma-GTP in human fetal organs. Histochemistry, 51: 209-218, 1977.

12) Fujisawa, K., Kurihara, N., Nishikawa, H., Kimura, A. and Kojima,M.: Carcino-embryonic character of gamma-glutamyl transpeptidase in primary hepatocellular carcinoma. Gastroenterol. JPN., 11: 380-386, 1976.

13) Girino, M., Invernizzi, R., Perseghin, P. and Michienzi, M.: Cytochemical study of gammaglutamyl transpeptidase activity in normal blood cells and in blood malignancies. Haematologica (PAVIA), 70: 266-268, 1985.

14) Groscurth, P., Fleming, N. and Kistler, G.: The activity and distribution of gammaglutamyl transpeptidase in human lung cancers serially transplanted in nude mice. Histochemistry, 53: 135-142, 1977.

15) Hada, T., Higashino, K., Yamamoto, H., Okochi, H., Sumikawa, K. and Yamamura, Y.: Further investigations on a novel gammaGTP in human renal carcinoma. Clin. Chim. Acta, 112: 135-140, 1981.

16) Hattori, N. and Sawatake, K.: Hepatocellular carcinoma. Tumor marker, ed. Urushizaki, I. and Hattori, N., pp. 196-199, Igaku-Shoin, Tokyo, 1985. (in Japanese)

17) Ianaccone, P.M. and Koizumi, H.: Pattern and rate of disappearance of gamma-glutamyl transpeptidase activity in fetal and neonatal rat liver. J. Histochem. Cytochem., 31: 1312$1361,1983$.

18) Igarashi, T., Satch, T., Ueno, K. and Kitagawa, H.: Changes of gamma-GTP activity in the rat during development and comparison of the fetal liver, placental and adult liver enzymes. Life Sciences, 29: 483-491, 1981.
19) Jaranko, H., Tapio, R., Lehtonen, E. and Ruoshauti, E.: Gamma-GTP in human amniotic fluid and in fetal tissues. Clin. Chim. Acta, 134: 3037-346, 1983.

20) Kinoshita, S. and Sakamoto, Y.: Glutathione. pp. 12, Kohdansha Scientific, Tokyo, 1985. (in Japanese)

21) Kreil, G.: Transfer of proteins across membranes. Ann. Rev. Biochem., 50: 317-348, 1981.

22) Meister, A., Tate, S.S. and Griffith, O.W.: Gamma-glutamyl transpeptidase. Meth. Enzymol., 77: 237-253, 1981.

23) Nachlas, M.M., Monis, B., Rosenblatt, D. and Seligman, A.M.: Improvement in the histochemical localization of leucine aminopeptidase with a new substrate, L-leucy-4-methoxy2-naphtylamide. J.Biophys. Biochem. Cytol., 7: 261-264, 1960.

24) Nelson, J.F., Feligio, L.S., Randall, P.K., Sims, C. and Finch, C.E.: A longitudinal study of estrous cyclicity in aging C57BL/ $6 \mathrm{~J}$ mice (cycle frequency, length, and vaginal cytology.) Biology of reproduction, 27: 327-339, 1982.

25) Novogrodsky, A., Tate, S.S. and Meister, A.: Gamma-glutamyl transpeptidase, a lymphoid cell surface marker; Relationship to blastogenesis, differentiation and neoplasia. Proc. Nat. Acad. Sci. USA, 73: 2414-2418, 1976.

26) Peterson, L.L., Zettergren, J.G. and Wuepper, K.D.: Biochemistry of transglutaminase and cross-linking in the skin. J. Invest. Dermatol., 81: $95 \mathrm{~s}-100 \mathrm{~s}, 1983$.

27) Richards, W.L., Tsukada, Y. and Potter, V.R.: Phenotypic diversity of gamma-glutamyl transpeptidase activity and protein secretion in hepatoma cell lines. Cancer Res., 42: 1374$1383,1982$.

28) Rutenburg, A.M., Kim, H., Fishbein, J.W., Hanbeer, J.S., Wasserkrug, H.L. and Seligman, A.M.: Histochemical and ultrastractural demonstration of gamma-glutamyl transpeptidase activity. J. Histochem. Cytochem., 17: 517-526, 1969.

29) Sakai, H : Glutathione in Medicine. ed. to Chiryosya, Tokyo, 1972. (in Japanese)

30) Takasaki, S. and Yamashita, K.: The glycoprotein of the cell membrane. Tumor marker. ed. Urushizaki, I. and Hattori, N. pp. 105112, Igaku-shoin, Tokyo, 1985. (in Japanese)

31) Takeuchi, T.: Enzyme histochemistry, 159174, Gakusai Nikaku, Tokyo, 1981. (in Japanese)

32) Tsuji, A., Matsuda, Y. and Katunuma, N.: 
Studies on the structure of gamma-glutamyl transpeptidase. J. Biochem., 87: 1567$1571,1980$.

33) Tomita, M., and Marchosi, V.T.: Amino-acid sequence and oligosaccharide attachment sites of human erythrocyte gly cophorin. Proc. Natl. Acad. Sci. USA, 72: 2964-2968, 1975.

34) Vanderlaan, $M$. and Phares, W.: Gammaglutamyl transpeptidase; A tumor cell marker with a pharmacological function. Histochem. J., 13: 865, 1981.

35) Wachstein, M. and Meisel, E.: J. Histochem.
Cytochem., 4,592. 1956. Sited from "Enzyme histochemistry". Ogawa, K. and Takeuchi, T. pp. 323 and 327, Asakura Shoten, Tokyo, 1980. (in Japanese)

36) Wiseks, and Müller, E.: Gamma-glutamyl transpetidase in human nephroblastoma grown in nude mice. Experientia, 32: 294-296, 196.

37) Yamashita, S., Yamamoto, N. and Yasuda, K.: Immunohistochemical study of lactate dehydrogenase isozymes in rat liver. Acta. histochem. cytochem., 12: 125-140, 1979. 


\section{Explanation of Figures}

\section{Plate I.}

Fig. 1. Localization of gamma-GTP in the esophago-gastric junction. Paraffin section, $\times 80$.

Tissue blocks were fixed in $4 \%$ paraformaldehyde for 4 hours at $4^{\circ} \mathrm{C}$ and then embedded in paraffin. The section was stained by the enzyme histochemical method of Rutenburg (28). The relationship between the esophagus and the stomach in the human may correspond to that between the forestomach (FS) and the glandular stomach (GS) in rodents. Gamma-GTP is present in the superficial layers of the stratified squamous epithelium on the fore-stomach side of the transitional zone, as shown in the right side of this photograph (FS). Positive reaction was not seen either in the columnar epithelial cells in the glandular stomach (GS) or in the stratified squamous epithelial cells apart from the transitional zone in the fore-stomach(A).

Fig. 2. Localization of gamma-GTP in the esophago-gastric junction. Paraffin section, $\times 1250$.

Reaction products are seen in the upper layer of the stratified squamous epithelium on the forestomach shown in the center of this photograph (FS). The simple columnar epithelium on the glandular stomach (GS) is seen in the right side of the photograph.

\section{Abbreviation words in Fig. 1 and 2}

FS: Stratified squamous epithelium on the fore-stomach side of the transitional zone.

GS: Columnar epithelial cells on the glandular stomach

A: Stratified squamous epithelium apart from the transitional zone in the fore-stomach 

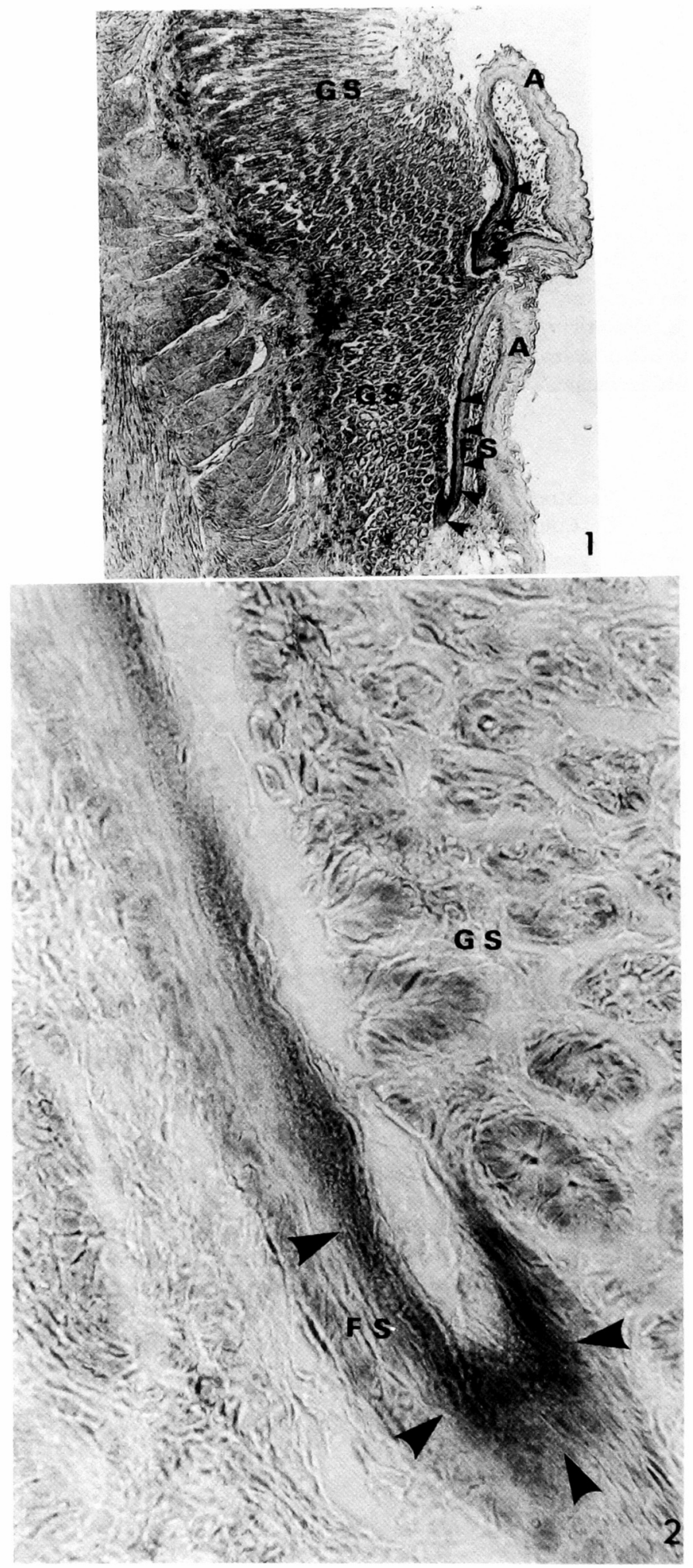


\section{Plate II}

Fig. 3. Localization of gamma-GTP in the utero-vaginal junction. Frozen section, $\times 625$.

Gamma-GTP is present in the superficial layers of the stratified squamous epithelium of the transitional zones in the utero-vaginal junction (arrow head $\boldsymbol{\nabla}$ ). The columnar epithelial cells in the uterus side $(\mathrm{U})$ revealed no gamma-GTP activity.

\section{Abbreviation words in Fig. 3}

V: Stratified squamous epithelium in the vaginal side

U: Columnar epithelial cells in the uterus side

Fig. 4. Distribution of gamma-GTP in the recto-anal junction. Paraffin section, $\mathbf{x} 200$.

Gamma-GTP activity is present in the superficial layers of the stratified squamous epithelium of the transitional zone in the recto-anal junction arrow. However, in the stratified squamous cells in contract with the columnar epithelia (B), gamma-GTP activity is also seen in the cells of deep layer (arrow head ). No activity is seen in the simple columnar epithelium of the rectum, as shown in the right side of this photograph (R) and in the stratified squamous epithelium apart from the transitional zone, as shown on the left corner (C) of this photograph.

Fig. 5. Localization of gamma-GTP in the recto-anal junction. Frozen section, $x 625$.

Tissue blocks were fixed in $4 \%$ paraformaldehyde for $4 \mathrm{hr}$ at $4^{\circ} \mathrm{C}$, and then frozen sections were prepared.

Gamma-GTP activity is present only in the superficial layer of the stratified squamous epithelium in the transitional zone.

Fig. 6. Distribution of ALP in the recto-anal junction. Frozen section, $x 625$.

Frozen sections were prepared in the same manner as for Figure 5. The sections were stained according to Burstone's method with naphthol AS-MX and fast blue BBN. ALP activity is present only in the superficial layer of the stratified squamous epithelium in the transitional zone. These location of ALP is almost the same as that of gamma-GTP in Figure 5.

\section{Abbreviation words in Fig. 4 and 5 and 6}

R: Columnar epithelial cells on the rectum

A: Stratified squamous epithelium on the anus

B: Stratified squamous epithelial cells in contact with the columnar epithelia

C: Stratified squamous epithelium apart from the transitional zone. 

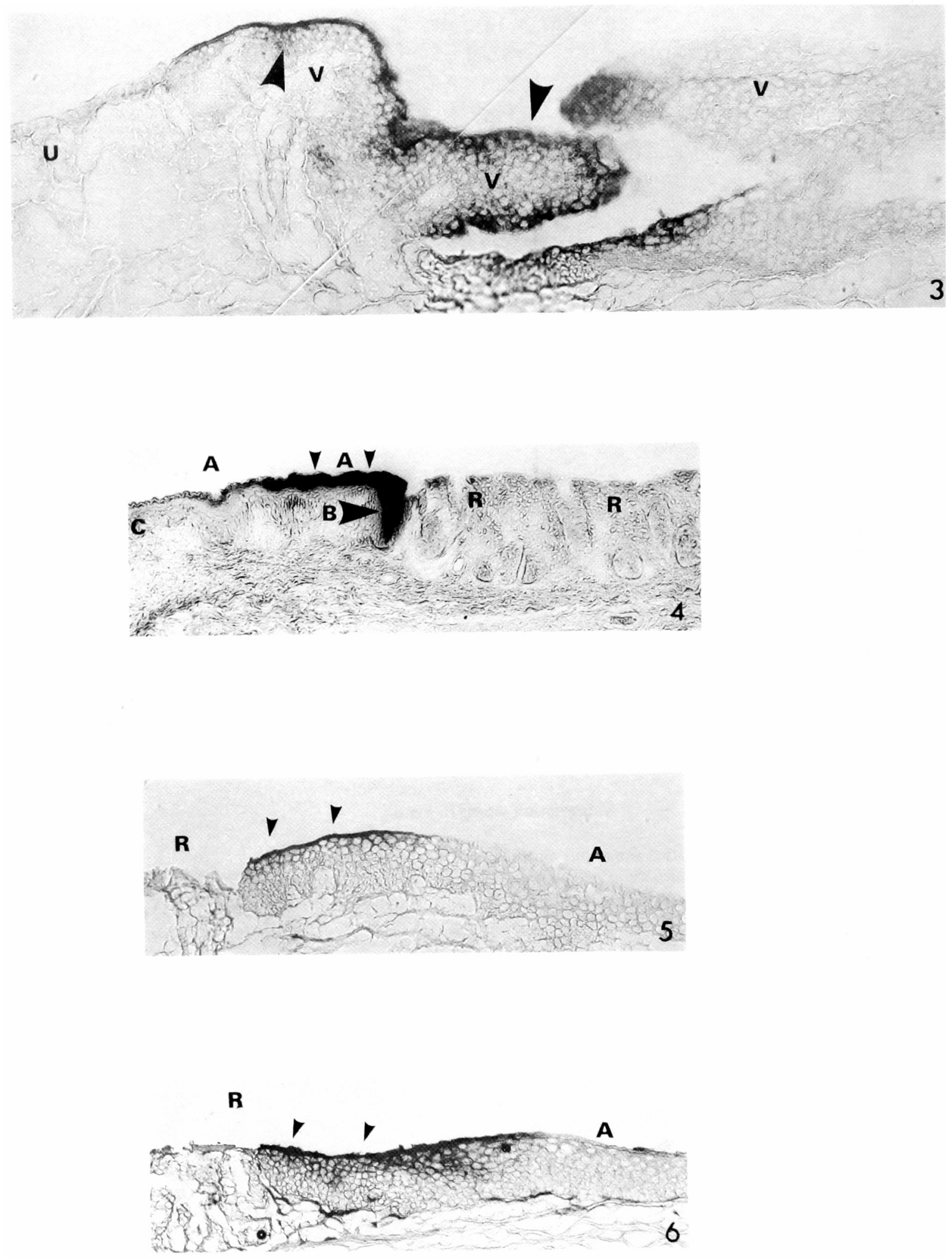


\section{Plate III}

Fig. 7. Localization of gamma-GTP in the excretory duct of the laryngeal gland. Paraffin section, $\times 1250$. This photograph shows the excretory duct of the laryngeal gland which is continuous with the stratified squamous epithelium (E). In this area, the simple columnar epithelium leading to the terminal portion on the right side of the picture (T) changes to the stratified squamous epithelium which leads to the opening of the gland on the left side (O). Gamma-GTP activity is seen in the stratified squamous epithelium (arrow).
Abbreviation words in Fig. 7
E: Stratified squamous epithelium in the excretory duct of the laryngeal gland
$\mathrm{T}$ : Columnar epithelial cells in the terminal portion of the laryngeal gland
$\mathrm{O}$ : Stratified squamous epithelium in the opening of the laryngeal gland

Fig. 8. Localization of gamma-GTP in the fossa navicularis. Paraffin section, $\times 200$.

This photograph shows the opening of the urethra $(0)$. Fossa navicularis is in the center $(N)$, and stratified squamous epithelium in this area is gamma-GTP positive. The left side of this photograph is toward the urethra $(\mathrm{U})$. The right side shows the urethral opening $(\mathrm{O})$.

Gamma-GTP activity becomes stronger towards the fossa navicularis but disappears just before the opening of the urethra. In this transitional zone the epithelium changes from stratified columnar to stratified squamous epithelium.

Abbreviation words in Fig. 8

N: Stratified squamous epithelium in the fossa navicularis

U: Columnar epithelial cells of the lower part of the urethra

$O$ : Stratified squamous epithelium of uriffic of the urethra 

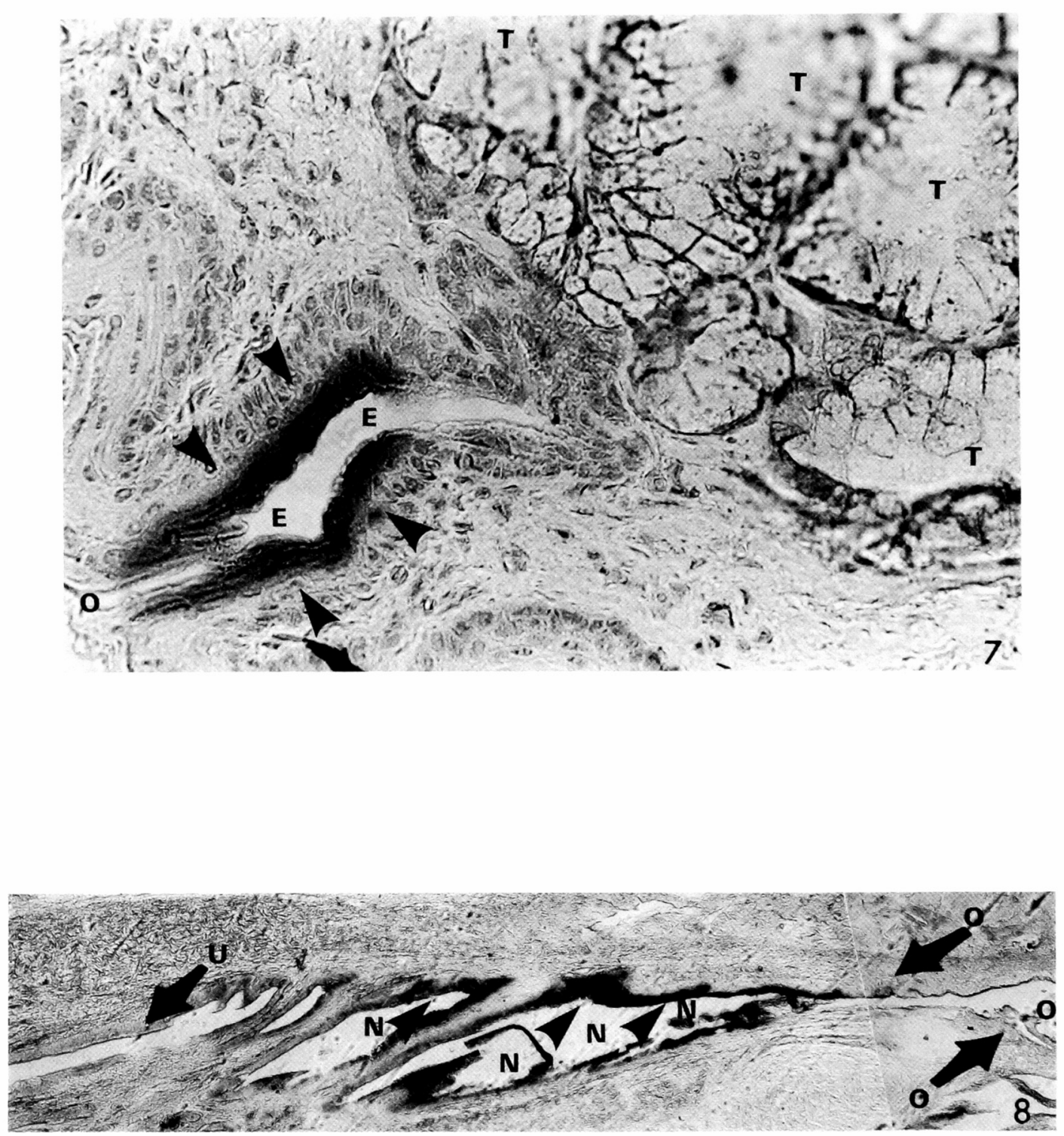


\section{Plate IV}

Fig. 9. Distribution of gamma-GTP in the larynx and the pharynx. Paraffin section, $\times 125$.

Between the larynx and the pharynx, the epithelium changes from stratified squamous to pseudostratified ciliated epithelium. This photograph contains three transitional zones. One is the junction between the oral pharynx and the larynx shown at the epiglottis (arrow head OPL $\nabla \nabla$ ). The second is the junction between the nasal pharynx and the esophagus (arrow NPE ). The third is the junction between the larynx and the esophagus (small arrow head LE $\nabla \nabla$ ), but the epithelium of the larynx is not seen in this figure. Gamma-GTP activity is located in the three transitional zones. The oral pharynx and the esophagus have stratified squamous epithelium. The nasal pharynx and the larynx have pseudo-stratified ciliated epithelium.

\section{Abbreviation words in Fig. 9}

OPL. Transitional zone between the stratified squamous epithelium of the oral pharynx and the pseudo-stratified ciliated epithelium of the larynx

NPE: Transitional zone between the pseudo-stratified ciliated epithelium of the nasal pharynx and the stratified squamous epithelium of the esophagus

LE: Transitional zone between the pseudo-stratified ciliated epithelium of the larynx and the stratified squamous epithelium of the esophagus

OP: Oral pharynx

NP: Nasal pharynx

Ep: Eipglottis

E: Esophagus 


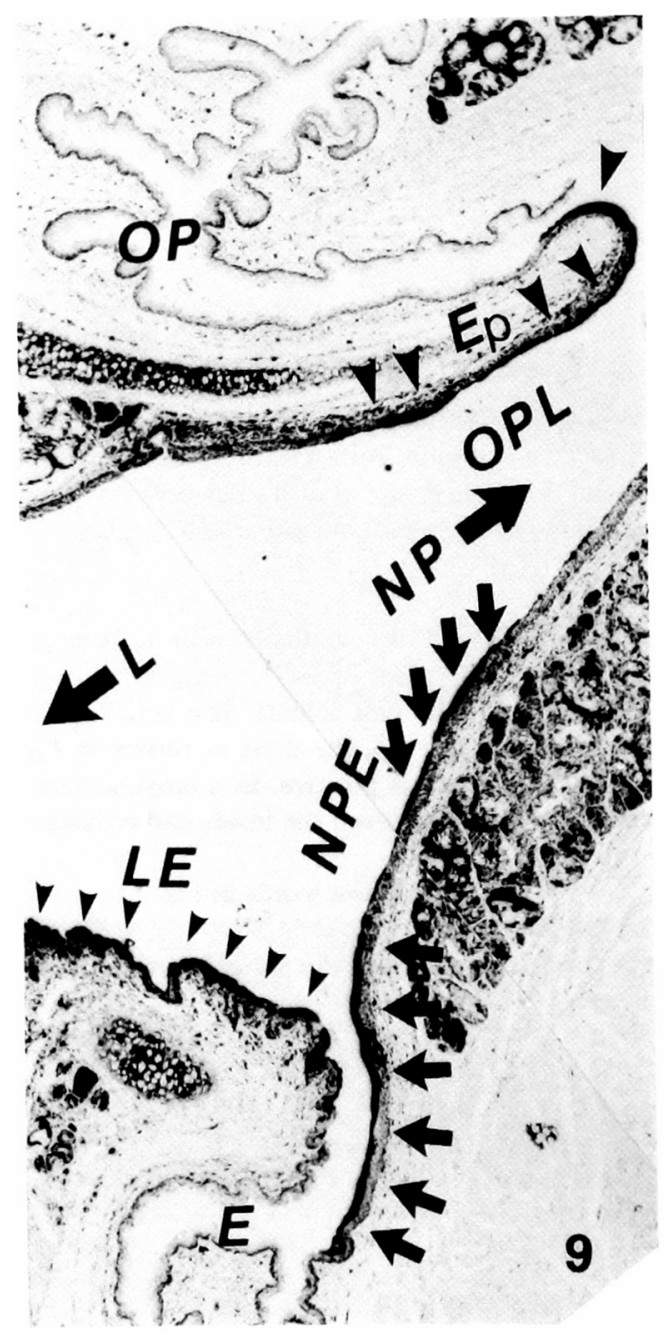




\section{Plate V}

Fig. 10. Distribution of gamma-GTP in the epithelial hair follicle cut longitudinally. Paraffin section, $x 125$. Gamma-GTP activity is seen in the inner root sheath of the hair follicle (arrow). When the hair is cut longitudinally as shown in this figure, the transitional portion is also seen between the upper and lower areas, taking the opening of the sebaceous gland as a cardinal point.

Fig. 11. Localization of gamma-GTP in the epithelial hair follicle cut transversely. Paraffin section. $\times 1250$

Gamma-GTP activity appears inside the hair follicle. The activity disappears in the portion above the place where the sebaceous glands open (S), the same as shown in Fig. 10. Accordingly, it is the inner root sheath where gamma-GTP activity is positive. In a cross section of the hair follicle, as shown in this photograph, the transition is seen between the inside and outside of the hair follicle.

Abbreviation words in Fig. 11

S: The portion situated above the place where sebaceous glands open 

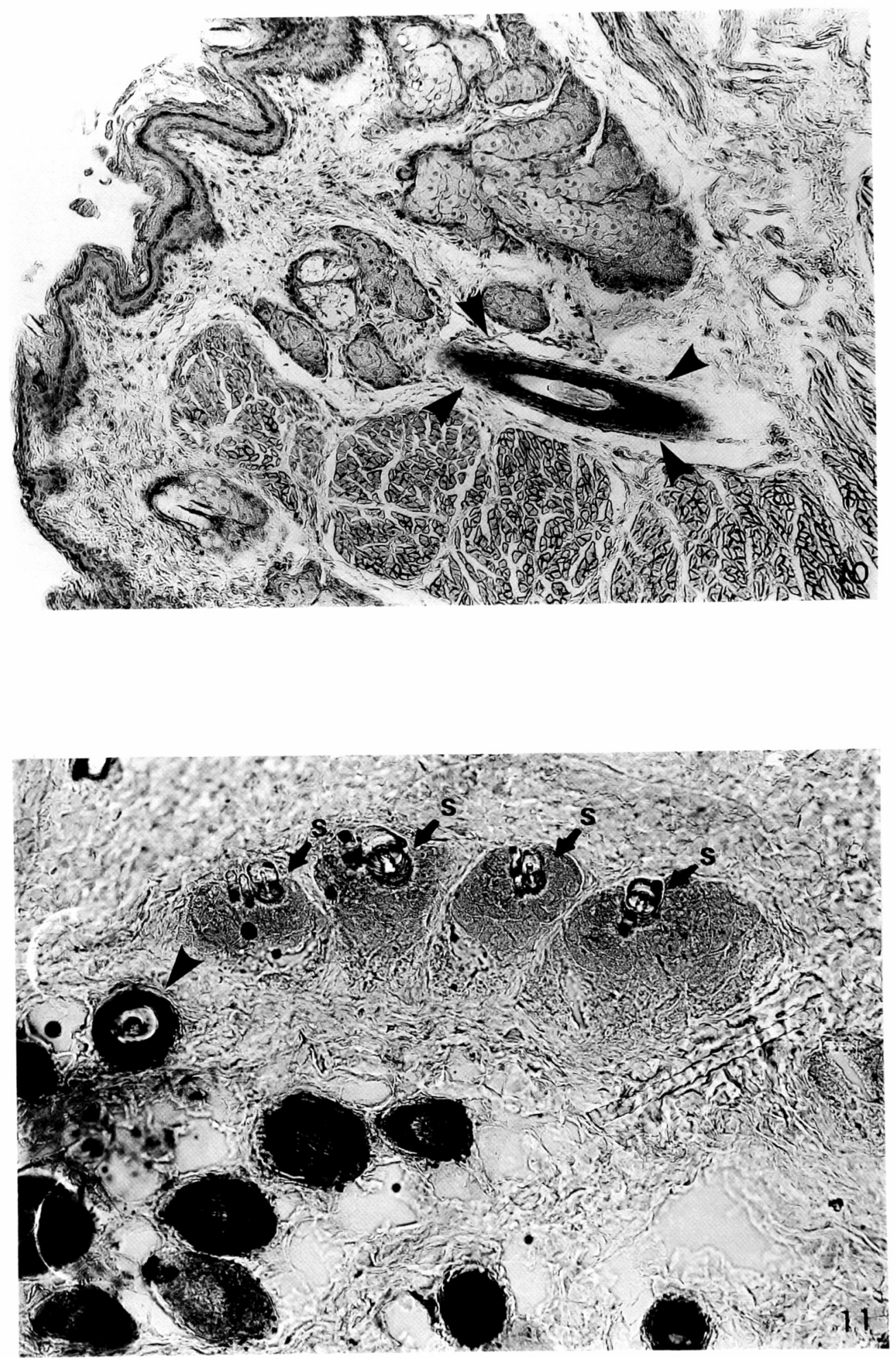